\title{
Health effects of infant feeding: Information for parents in leaflets and magazines in five European countries
}

Public Understanding of Science 22(3) 365-379

(C) The Author(s) 2012

Reprints and permissions: sagepub.co.uk/journalsPermissions.nav

DOI: $10.1177 / 0963662511435452$ pus.sagepub.com

(B) SAGE

\author{
Heather Gage', Julia Von Rosen-Von Hoewel', Kirsi Laitinen³,

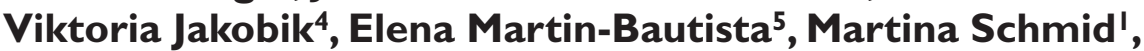 \\ Bernadette Egan', Jane Morgan', Peter Williams', Tamas \\ Decsi $^{4}$, Cristina Campoy ${ }^{5}$, Berthold Koletzko ${ }^{2}$ and Monique \\ Raats' \\ 'University of Surrey, UK \\ ${ }^{2}$ Ludwig-Maximilians University, Germany \\ ${ }^{3}$ University of Turku, Finland \\ ${ }^{4}$ University of Pécs, Hungary \\ ${ }^{5}$ University of Granada, Spain
}

\begin{abstract}
Parents' decisions about whether to breastfeed their infant, and when to introduce complementary foods, are important public health issues. Breastfeeding has beneficial health effects and is widely promoted. Leaflets and magazine articles on infant feeding were collected in 2005, in five European countries (England, Finland, Germany, Hungary, Spain), and screened for statements that link feeding behaviours to infant health outcomes. A total of 127 leaflets contained 512 statements ( $0.38 /$ published page). Magazines contained approximately I article / month. Health outcomes were more intensively covered in England and Germany. Most statements referred to short term health implications. Lack of scientific agreement may underlie lack of cover of longer term health effects. Scope may exist to promote improved infant feeding practices by increasing the quantity and specificity of messages about health effects. Further research is required to evaluate the impact of alternative means of providing information on infant feeding practices.
\end{abstract}

\section{Keywords}

European countries, health effects, infant feeding, leaflets, magazines, scientific agreement

Corresponding author:

Heather Gage, Department of Economics, University of Surrey, Staghill, Guildford, Surrey GU2 7XH, England, UK.

Email:h.gage@surrey.ac.uk 


\section{Introduction}

Parents' decisions about whether to breastfeed or use formula milks for their infants, and at what age to introduce complementary foods, are important public health issues. Breastfeeding is widely promoted by national and international agencies and health care professionals because of its beneficial health effects. Following an extensive review of available evidence, the World Health Organisation issued a global recommendation that babies should be exclusively breastfed for six months (World Health Organisation, 2001). Formula milks are associated with a range of short term health problems for babies, especially gastric and respiratory tract infections, and the health consequences of not breastfeeding extend to childhood, adolescence and beyond (American Academy of Pediatrics, 2005; World Health Organisation Europe, 2007). The concept of "programming" suggests that the nutritional environment in the early months of life may "set" a child's metabolism and influence lifelong health (Delisle, 2002; Horta et al., 2007), and links poor nutrition in the prenatal and early post-natal period to considerable disease burden, including obesity (von Kries et al., 1999), allergies (Chandra, 2002), diabetes (Virtanen and Knip, 2003) and cardiovascular conditions (Singhal et al., 2003).

Several recent studies have found low rates of breastfeeding and poor weaning practices in Europe, and public health nutrition policy for infants and young children is focussed on increasing breastfeeding initiation rates and duration (Nichol et al., 2002; World Health Organisation Europe, 2003; European Commission, 2004; Cattaneo et al., 2005; World Health Organisation, 2007a). In this context, the information environment facing consumers is important. The target audience is the parents and other caregivers who make decisions about nutrition on behalf of their babies and young children. Agencies need to ensure that messages about the health advantages of breastfeeding are communicated in a way that will have a positive effect on the behaviours of these decision makers. Caregivers' choices may be influenced by a variety of factors, including convenience and cost (Murphy et al., 1998; Shaw et al., 2003; Stewart-Knox et al., 2003), and the health implications for infants may not be paramount.

One method of informing consumers is to issue policy documents containing practice recommendations for health care professionals, and other agents, who deliver services to the relevant client groups. These guidelines should evolve from a robust synthesis of available evidence and consensus among stakeholders, including practitioners and service use representatives (Commission for European Communities, 2001; Renfrew et al., 2008). Advice from health care professionals has been shown to have a significant influence on individuals' health-related behaviours (Di Giraldamo et al., 2003; Lee and Garvin, 2003), and verbal communication may be reinforced by a variety of electronic, print and visual media that target consumers directly. To ensure that messages about health risks and benefits are communicated persuasively, conceptual approaches from psychology emphasise a need to focus on cognitive processes that mediate behaviour change (Ogden, 2007). Protection motivation theory (Rogers, 1983), for example, suggests that the likelihood of individuals adopting health protecting behaviours, such as breastfeeding, depends on their perceptions of the severity of the threat (adverse health effects for the infant of not breastfeeding), probability of the threat occurring (or their vulnerability to it), efficacy of the recommended protective behaviour (exclusive breastfeeding for six months), and self efficacy (confidence) that they can perform the preventive behaviour.

This paper reports findings from a study that explored the representation of health implications of infant feeding choices in the first year of life (milk feeding and introduction of complementary foods) in widely distributed consumer information in five European countries (England, Finland, Germany, Hungary and Spain). It sought to establish whether the content of leaflets and 
magazine articles on infant feeding covered health effects for the infant, and if so, the range and specificity of outcomes mentioned. It aimed to identify the extent and way in which the "threat" arising from poor infant nutrition practices was communicated to caregivers through these media.

Written materials (leaflets and small booklets) were chosen for study as they are a commonly used means of promoting infant feeding messages to parents. They are inexpensive to produce, easy to distribute (by health professionals, in retail establishments and other public places), and provide convenient reference sources. They have been shown effective at improving knowledge in other health areas (Castle et al., 1999; O'Cathian et al., 2002), and in counteracting misinformation that parents may acquire from other sources such as relatives, friends, or non-validated websites (Caroline Walker Trust, 2007). Similarly articles in parenting magazines have the potential to reach target groups, particularly since readership exceeds published circulation figures through placement of magazines in locations such as doctors' waiting rooms.

The study reported here was part of a larger project, a parallel component of which investigated the lifelong health outcomes associated with breastfeeding in policy documents (in the same five countries). This analysis found no consistency within or between countries in the way in which health risks or benefits were cited as factors in recommendations for breast rather than for formula feeding (Martin-Bautista et al., 2010). The observed variability may be attributable to uncertainty in the underlying science. Differences exist, for example, in the extent to which the protective effect of breastfeeding is endorsed with respect to allergy (World Health Organisation, 2001; Agency of Healthcare Research and Quality, 2007; Kramer et al., 2007) and long term conditions (Chandra, 2002; American Academy of Pediatrics, 2005; Agency of Healthcare Research and Quality, 2007). In addition, reservations have been expressed about whether the World Health Organisation (2001) global recommendation of exclusive breast feeding for six months is optimal for all babies (Fewtrell et al., 2007; ESPGHAN, 2008; Cattaneo et al., 2011). Inconclusive or insufficient scientific evidence such as this may also be expected to impact on the content of consumer information, where the additional problem of communicating technical issues in an accurate and understandable way to a lay audience has to also be addressed.

\section{Methods}

The countries in the study were selected to represent geographical spread within Europe and varied socio-economic structures and health economies. Standard operating procedures were agreed amongst partners through regular face-to-face meetings and email contact to ensure each element of the work was conducted in the same way in each country.

A search for leaflets (defined to include small booklets and information sheets) was conducted simultaneously in each country between July and October 2005 through an open internet search and by targeting the websites of relevant organisations (national and regional government agencies, professional associations, interest groups, retail and manufacturing industries) using the key words: nutrition, diet, breastfeeding, bottle feeding, formula feeding, weaning, complementary feeding, infant feeding and baby (in local languages). Leaflets were collected if they referred to the feeding or nutrition of healthy infants aged $0-12$ months and were dated 2000 or later. This cut-off date was selected to ensure recent editions were incorporated, and to keep the volume of data manageable. Materials targeting pregnancy, older children or health professionals or focussing on legal or practical aspects were excluded. Titles, bibliographic information and a brief description of the leaflets (subject area: milk feeding, complementary feeding, both; 
authorship: national / regional government, professional association, special interest group, industry; price; number of pages in A4 equivalent; use of illustrations: yes / no) were stored in English.

Each selected leaflet was independently screened by two people in each country and statements that related breastfeeding, formula feeding or a complementary feeding behaviour to a health outcome for the baby were agreed and extracted. Where a health outcome was repeated in consecutive sentences, only the first occurrence was included for analysis. Statements on non-nutritive substances (e.g. alcohol) and toxicological substances (e.g. mercury), nutrient absorption and supplementation (e.g. vitamins, folic acid), and the effects of special diets (e.g. vegan) or malnutrition were excluded. If in doubt about the eligibility of a statement, researchers were instructed to include it, and that it would be removed, if necessary, at a later stage. Statements were entered verbatim into an SPSS version 15 database to facilitate manipulation of the data. Where necessary, an English translation was provided which was checked by researchers in England and referred back to individual countries for clarification if issues of comprehension arose.

The most popular monthly parenting magazine for each country (defined on the basis of annual average circulation figures) was identified. All 12 issues from January to December 2005 were screened by two independent researchers in each country for articles (including notes or comments) on the feeding or nutrition of healthy infants aged 0-12 months. Articles on nutrition in pregnancy or for toddlers, and advertisements or promotional text were excluded. Statements that related a feeding behaviour to a health outcome for the baby were identified in each article and processed in the same way as the statements from leaflets.

Coding of statements was undertaken separately for milk feeding and complementary feeding, since the issues and health implications for infants are different. In each case it was driven by the data in the statements, as originally presented. An initial list of 47 health outcomes associated with milk feeding behaviours was compiled from reading of the documents in all five countries. A refined list of 22 health benefits associated with breast rather than formula feeding (in four main categories: health in general; infections; allergy; long term conditions) was produced by researchers in England. This was based on the number of statements in each category, and to ensure consistency with classifications used in national and international documents (Weiner, 2001; American Academy of Pediatrics, 2005; World Health Organisation, 2007b). Coding of health outcomes in statements referring to complementary feeding followed a similar procedure and resulted in the establishment of 23 health effects (in five major categories: food allergy; food poisoning; links to long term health conditions; other health reasons; establishing good eating habits). No distinction was drawn between an outcome that was expressed as a positive statement about breastfeeding (e.g. breastfeeding reduces the risk of gastrointestinal infections) or as a negative statement about formula feeding (e.g. the risk of gastrointestinal infections is higher for babies that are formula fed): both were coded as a statement relating to gastrointestinal infection. Statements referring to milk feeding were additionally coded by type of feeding behaviour (exclusive breastfeeding for unspecified duration, $<4$ months, 4-6 months, $\geq 6$ months; breastfeeding in general of unspecified duration; formula feeding). Coding of health outcome statements to these reduced lists of categories was undertaken in individual countries.

Two independent researchers in England (HG, JM) reviewed the statement selection and coding across all five countries. This validation stage was important to ensure consistency between countries. About a quarter of statements included by researchers in individual countries were dropped at this point: those in leaflets about milk and complementary feeding were reduced from 504 to 395 (21.6\%) and 182 to 117 (35.7\%) respectively; those in magazines were similarly reduced from 172 
to $121(29.7 \%$, milk feeding) and 115 to 76 (33.9\%, complementary feeding). Typically statements were removed because they related to nutrition in childhood and adolescence (rather than in the first year of life), referred to the effect of supplements (e.g. iron or iodine) or special sorts of milk (e.g. soya and probiotic), or to a health benefit for the mother (rather than the infant). Changes to codings allocated to individual statements in individual countries also took place at this stage. All coding amendments were agreed through discussion between the assessors, resulting in an overall revision rate of $12.1 \%(44 / 395,11.1 \%$ of statements about milk feeding in leaflets; $15 / 121,12.4 \%$ milk feeding magazines; 17/117, 14.5\% complementary feeding leaflets; $10 / 76,13.2 \%$ complementary feeding magazines). At the end of this process, an internally consistent master database had been established as a basis for analysis. Following principles of documentary analysis, findings are reported in terms of statements per leaflet and how many times issues are mentioned (May, 1993).

\section{Results}

\section{Availability of written information: Leaflets and magazines}

The search for leaflets revealed 127 separate publications. The majority ( $n=58,45.7 \%$; range $12 \%$ Finland to $61 \%$ Spain) covered just milk feeding, fewer than one fifth $(n=22,17.3 \%)$ covered just complementary feeding, and the rest covered both feeding behaviours. Relatively few of the leaflets were identified in Finland $(n=8)$ and Germany (13), compared to Spain (33), England (35) and Hungary (38). Most publications were free of charge (or very inexpensive), relatively short and contained pictures or illustrations (Table 1). At least half of the leaflets in Finland and Hungary were produced by special interest groups (e.g. breastfeeding support groups), and in Germany were produced by manufacturers or retailers of formula milk or infant foods. Government sources were involved most often in England and Spain. A total of 512 health outcome statements were identified from these leaflets, an average of 0.38 statements per published page (range 0.13 Finland to 0.85 England). The magazines ranged in price from 1 Euro (Finland) to 3 Euros (England) per issue, and had average annual circulations of between 13 (England) and 148 (Spain) issues per 10,000 inhabitants. Issues were typically around 100 pages, except in England (average 180).

\section{Statements about health outcomes in leaflets and magazine articles that covered milk feeding}

A total of 395 statements about the implications for the baby of the choice between breast and formula feeding were extracted from 105 leaflets across the five countries (mean 3.8 per leaflet, range 2.25 Finland to 4.3 England) (Table 2). Over one fifth of leaflets ( $n=24,22.9 \%$, and 12 of $35(34.3 \%)$ in Hungary) contained no statements. About one third of the statements referred to a range of general health benefits from breastfeeding (for example, that it resulted in "better health"), and a further third cited the protection afforded by breastfeeding against infections. The remaining statements were approximately equally divided between long term benefits (including prevention of obesity, diabetes and cardiovascular disease, and enhancement of immune function) and allergy protection.

The analysis of the content of the magazines revealed 56 articles on milk feeding (from a total of 60 issues across the five countries, 0.93 articles per issue), of which 44 (78.6\%) mentioned health implications for the baby of the choice between breast and formula feeding in a total of 121 


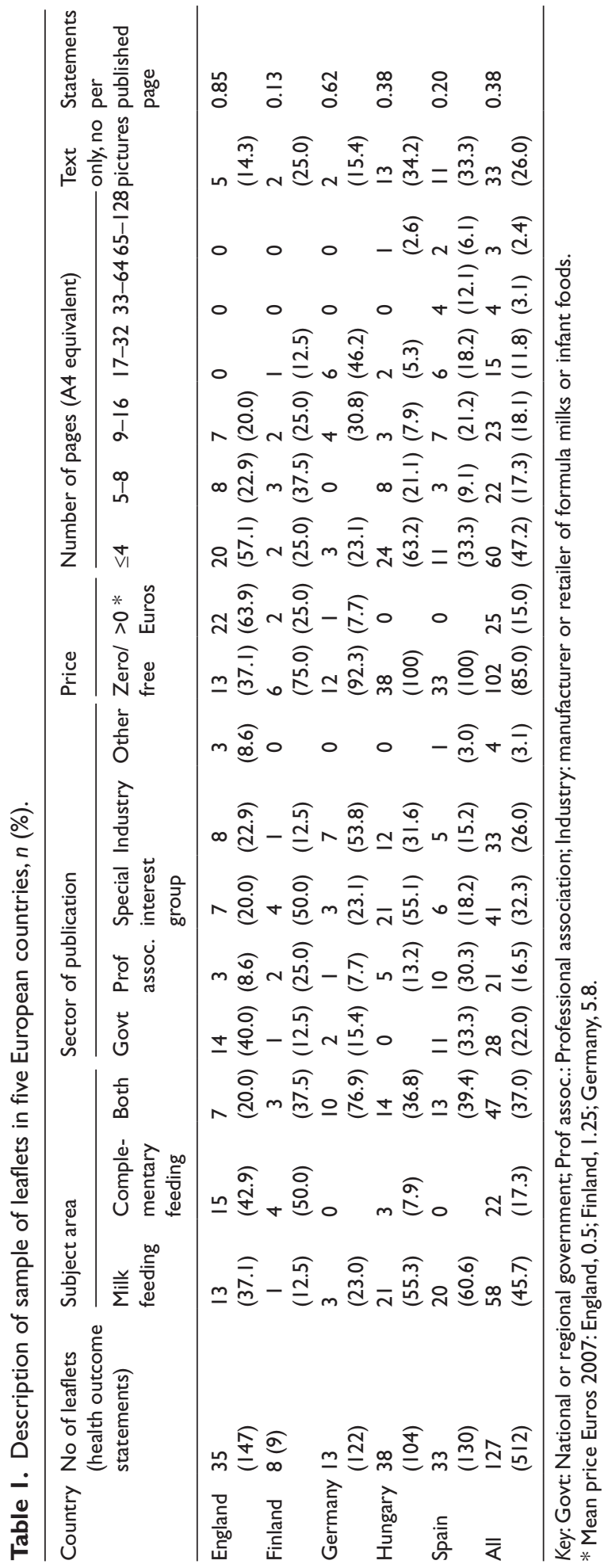




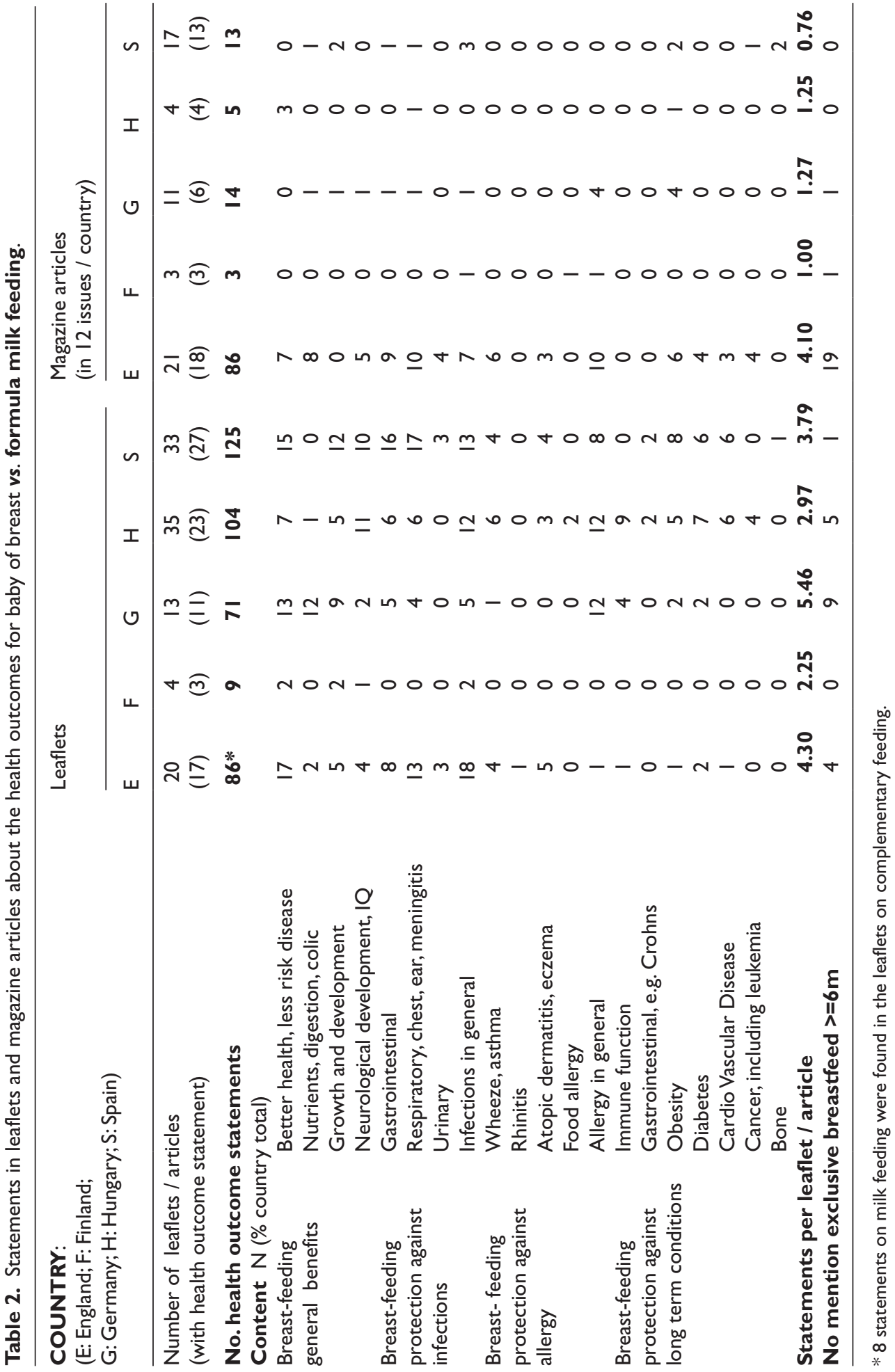


statements. The English magazine contained 86 of the statements ( $71 \%$ of the total). Few articles on infant feeding were found in the magazines in Finland and Hungary ( $n=3$ and 4 respectively), and the articles themselves contained little on health implications $(n=3$ and 5 statements respectively). Across all countries, protection against infection was the most frequently cited advantage of breastfeeding (33\% of all statements).

Variability between countries was observed in the extent to which statements emphasised different health outcomes. The predominant outcomes represented in leaflets on milk feeding related to infections in England and Spain, long term conditions in Hungary, and general benefits of breastfeeding in Germany and Finland. Statements from magazine articles on milk feeding in England also emphasised infection risks, but the small numbers of statements in the magazines of other countries make it difficult to identify particular patterns. A relatively low proportion of statements explicitly reflected the World Health Organisation (2001) recommendation for six months' exclusive breastfeeding: 19/395 (4.8\%) in leaflets, 21/121 (17.4\%) in magazine articles, of which 19 were in England (22\% of all English magazine statements).

\section{Statements about health outcomes in leaflets and magazine articles that covered complementary feeding}

A total of 117 statements on the health implications for the baby of complementary feeding behaviours were extracted from 69 leaflets across the five countries (Table 3). Overall, only $25(36.2 \%)$ of the leaflets contained health outcome statements, none in Finland or Hungary (vs. $n=10(100 \%)$ in Germany). Advice on complementary feeding focussed mostly on foods to avoid, particularly to protect against allergies ( $n=48,41 \%$ of statements), or for other health reasons, such as to prevent dental caries through avoidance of sugary foods or beverages $(n=17,14.5 \%)$. Long term conditions featured in $21(18 \%)$ of the statements.

The 60 magazines (12 issues in each of five countries) contained 26 articles on complementary feeding ( 0.43 per issue), of which $25(96.1 \%)$ contained a total of 76 health statements (none in Finland and Spain). Over half of the statements on complementary feeding were from the English magazine and one third from Germany. As with leaflets, allergy was the main health outcome mentioned ( $n=35,46.1 \%$ of statements), followed by long term conditions ( $n=16,21 \%)$, of which obesity was the most frequently cited.

\section{Discussion}

The study confirms that a range of infant feeding leaflets (covering both the milk feeding and the introduction of complementary foods) are available in the five countries included in this analysis. The documents are produced by a variety of agencies, and are mostly distributed freely, or are inexpensively priced. Analysis of the content of these materials showed that the health implications of infant feeding decisions are not widely discussed. On average, for every 2.6 published pages, there is one health outcome statement. However, this varies between countries from almost one statement per page in English leaflets to one statement every eight pages in Finland. Nearly one quarter of leaflets related to milk feeding, and two thirds of those related to complementary feeding, did not include any statements about the health effects for the baby of food choices.

Coverage of infant feeding in articles or notes in the main monthly parenting magazine in each country was also variable. The magazines in England, Germany and Spain publish at least one article on infant feeding per monthly issue ( 2 per issue in England), but only three or four articles 


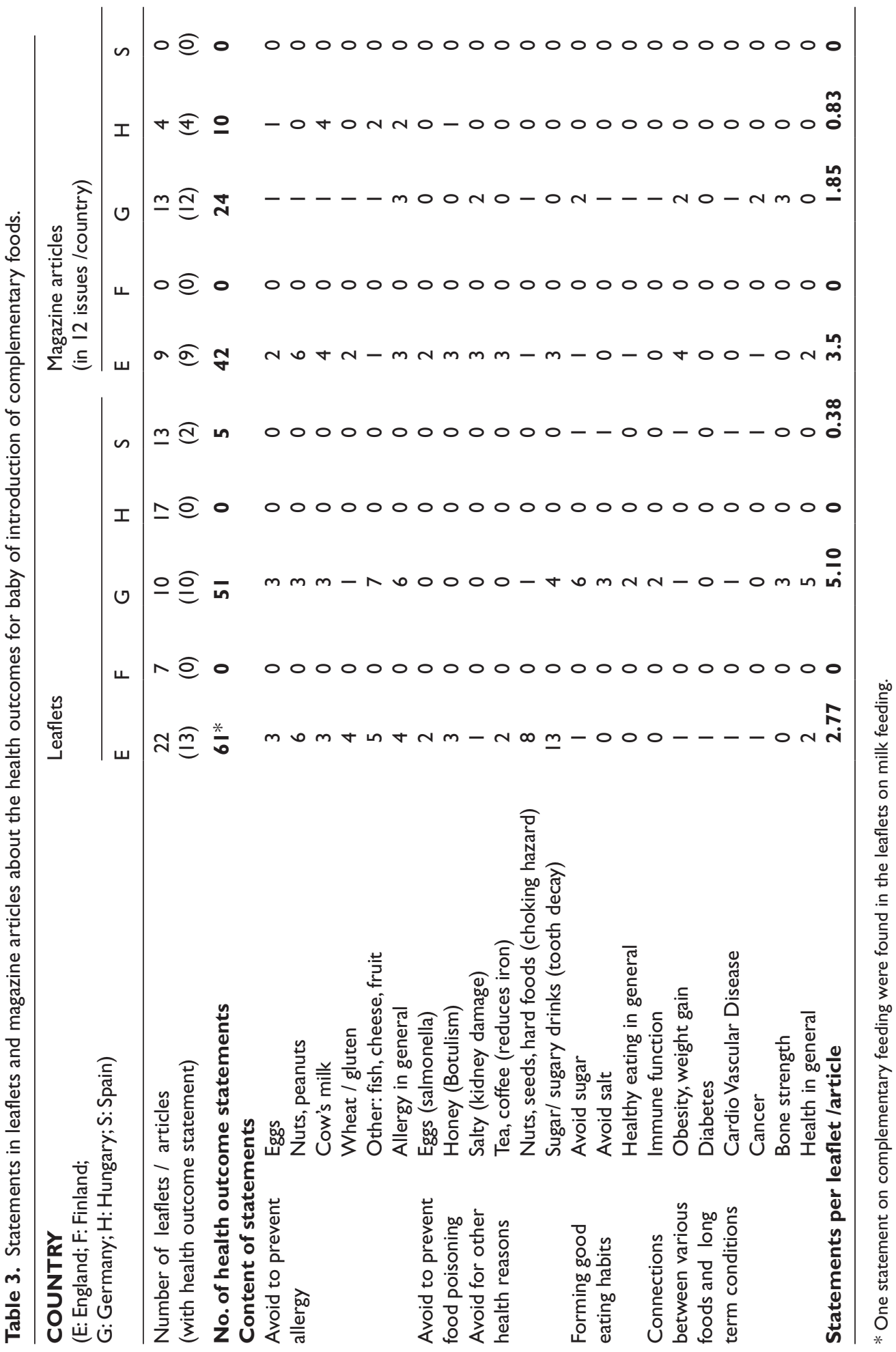


were identified during the whole 12 month data collection period in each of Finland and Hungary. Articles in magazines were more likely than leaflets to include a health outcome statement relating to complementary feeding $(96.1 \%$ vs. $36.2 \%)$.

Advice on complementary feeding in both leaflets and magazine articles tended to be specific, citing particular foods to avoid (peanuts, tea, honey, etc.) to prevent food allergy or other health problems. The content of statements relating to milk feeding was frequently vague, citing generic health benefits (for example, "breastfeeding is best") and short term implications such as protection against infections. Possible long term health effects of feeding choices accounted for around a fifth of both the milk and complementary feeding health outcome statements.

Recent analyses of the cover of other important public health issues in the print media have also reported deficiencies in information on preventive behaviours (Slater et al., 2008; Gollust and Lantz, 2009; Mathews et al., 2009), and variability in the content of messages (Friedman et al., 2010). The main focus of most of the leaflets and magazine articles identified in this study was on the practicalities of breastfeeding and of introducing new foods and beverages, rather than the consequences for lifelong health. Whilst understanding technical aspects of the feeding process has been shown to be important to encourage low income mothers to breastfeed (Hoddinott and Pill, 2000), further explanation of the health implications of decisions may also be warranted to help influence behaviours.

Protection motivation and other theories based in cognitive psychology suggest that communication of risks or benefits associated with different actions may help persuade individuals to adopt health promoting behaviours, particularly if a threat is perceived to be serious and they think they are susceptible. Providing information through media sources can improve knowledge and alter attitudes and health behaviours (Brown et al., 2001; Gollust and Lantz, 2009; Slater et al., 2009; Moriarty et al., 2010). The possible adverse effects of poor infant nutrition practices deserve to be fully and consistently explained to caregivers. However, risk perception is a complex psychological construct and behaviour modification is influenced by a variety of factors (including peer pressure, partner support and family circumstances), and the extent to which caregivers respond to education about infant nutrition is an empirical question. Longitudinal studies have found no relationship between the number of magazine articles on breastfeeding and breastfeeding rates (Potter et al., 2000; Foss et al., 2006), but carefully designed and delivered messages could affect views (Brown and Peuchaud, 2008), and such considerations should be investigated.

The greater attention in written materials to short term health effects of infant feeding decisions (e.g. infections or food allergy) rather than longer term consequences (the development of chronic conditions such as obesity, diabetes, cardiovascular disease and cancer later in life) would be consistent with protection motivation theory that purports that more immediate threats are more likely to be more effective at generating health protecting behaviours than threats that are remote. However, lack of cover of long term health effects, and absence of any mention of programming theories in any identified leaflet or magazine article, may be a reflection of greater uncertainty in the underlying science, and lack of consensus about mechanisms and impact. A parallel analysis of the content of policy documents on infant feeding in the same countries also noted that most attention focuses on short term rather than long term health implications (Martin-Bautista et al., 2010). Establishing an association between cause and effect is more difficult for longer term outcomes, and uncertainty surrounds research findings. Where the scientific evidence is insufficient or inconclusive, policies and associated information for consumers may be cautionary (European Union, 2000). On the one hand, there is a responsibility to inform of potential risks, but on the other, it is not known how the presentation of uncertainties and complexities in the scientific evidence affects the attitudes and behaviours of lay audiences. Some sections of the public may find information 
more trustworthy when uncertainties are reported (Jensen, 2008), but others may become confused and indecisive. More research is needed to explore how people process, interpret and respond to different types of uncertainty, and how personal characteristics and the means of communicating risks affect comprehension and behaviour change (Politi et al., 2007).

Whilst the overall picture across countries is that the health outcomes of infant feeding choices are not given high profile in leaflets and magazines, differences between countries are apparent. Generally there is a higher intensity of statements per document, and a wider range of health outcomes covered in the materials from England and Germany. The reasons underlying this are not known. In both countries, leaflets were issued by a range of types of organisations, although in England, in line with the centralised provision of health care (through the National Health Service) more came from government agencies, whereas in Germany, where health insurance is largely through occupation-based sickness funds, industry was the predominant publisher.

International comparisons of breastfeeding rates are restricted by limited availability of data and methodological differences (Cattaneo, 2009). Information is typically collated from a range of national sources, and indicates large variability amongst the study countries in the proportions of children (around 2005) exclusively breastfed at three and six months: Hungary 95\%, 42\%; Finland 50\%, negligible; Spain 41\%, 19\%; United Kingdom (UK) 10\%, negligible (OECD, 2009). An independent study (around the same time) in one region of Germany reports $42 \%$ exclusive breastfeeding at four months and $21 \%$ at six months (Kohlhuber et al., 2008). Many complicated cultural and personal factors underpin this international variation. Local policies related to maternity leave do not provide a complete explanation, as evidenced by the difference in breastfeeding rates in Hungary and the UK, both of which have relatively generous leave allowances (OECD, 2009). Written materials provide an opportunity to target country-specific barriers, and particular socio-economic segments of the population where attitudes are more resistant. It is not known whether simple messages, or more detailed and scientific explanations, are more effective at disseminating information and encouraging healthy behaviours, and this may vary both within and between countries. More research is required on this issue so that the content and presentation of documents can be customised accordingly.

The search for leaflets and extraction of health outcomes statements were conducted rigorously, In accordance with methodologies agreed in advance by partners in each country. Researchers met regularly to agree procedures and resolve any issues. The coding of statements was verified across countries by independent assessors. However, the study is limited in several ways. Although the five countries in the study were selected to provide geographical spread across Europe, they may not be representative of all social, political and health care systems. It is possible that leaflets could have been missed by the searches. The analysis of health effects is based on counts of statements. Frequencies have been used in other similar studies (Meister, 2004; Jones et al., 2008), but are not necessarily a good indication of overall significance. The materials were collected in 2005, and although most are still in circulation, referencing of health effects could have altered in later editions. Scientific knowledge could have advanced, and the importance of health as a factor influencing choices could have changed. However, the shift in the evidence base in this area is slow, and no new policies have been published. Future research is required to explore evolution in the representation of infant feeding messages in written materials for consumers.

In a survey of a sample of new mothers in the study countries, diet as a baby was perceived to be a less important influence on lifelong health than many lifestyle, behavioural and environmental factors, and genetics (Gage et al., 2011). Hence, scope may exist for public health policy makers to raise the profile of health as an influence on decisions that caregivers make about feeding their infant. Written materials are a potentially useful means of achieving this. Amongst the same 
sample of mothers, leaflets and magazines were ranked fourth and fifth in terms of importance as influences on their infant feeding decisions, behind their partner, antenatal midwife, staff in maternity units and books, and ahead of other relatives, friends, electronic media and television.

There is a need for further research to evaluate the impact on infant feeding practices of alternative means of providing information to parents in different socio-economic groups and cultural settings, including the effect of health professional endorsements, family and friends, and the growing importance of the internet and social networking sites. It is also important to explore how the importance of health factors can be enhanced in caregivers' decision making about infant feeding. Whilst variability is apparent, in general, the health effects of alternative feeding behaviours are not comprehensively or consistently portrayed in leaflets and magazine articles in the countries in this study, and scope may exist to promote improved infant feeding practices by increasing the quantity and specificity of messages about health effects in consumer information. Moreover, progress in this regard awaits definitive research conclusions and policy endorsements to remove existing uncertainties about the influence of infant feeding decisions on lifelong health.

\section{Acknowledgement}

The authors are grateful to anonymous reviewers for helpful comments on an earlier draft.

\section{Funding}

This study was supported as a part of the European Project "Early Nutrition Programming-EARNEST" within the 6th Framework Programme. N FOOD-CT-2005-007036.

\section{References}

Agency of Healthcare Research and Quality (2007) Breastfeeding and maternal and infant health outcomes in developed countries. Available at: http://www.ahrq.gov/clinic/tp/brfouttp.htm (accessed 1 July 2011).

American Academy of Pediatrics (2005) Policy statement: Breastfeeding and the use of human milk. Pediatrics 115(2): 496-506.

Brown JD and Peuchaud SR (2008) Media and breastfeeding: Friend or foe? International Breastfeeding Journal 3: 15-17.

Brown P, Zavestoski SM, McCormick S, Mandelbaum J and Luebke T (2001) Print media coverage of environmental causation of breast cancer. Sociology of Health and Illness 23: 747-775.

Caroline Walker Trust (2007) "I hear it's the closest to breast milk". Available at: www.cwt.org.uk (accessed June 2010).

Castle C, Skinner TC and Hampson S (1999) Young women and suntanning: An evaluation of a health education leaflet. Psychology and Health 14: 517-527.

Cattaneo A (2009) Breastfeeding - Occurrence. European Union Public Health Information System, Version 11.1, December. Available at: www.euphix.org (accessed 13 December 2011).

Cattaneo A, Yngve A, Koletzko B and Guzman LR (2005) Protection, promotion and support of breastfeeding in Europe: Current situation. Public Health Nutrition 8: 39-46.

Cattaneo A, Williams C, Pallas-Alonso CR, Hernandez-Aguilar MT, Lasarte-Velillas JJ, Landa-Rivera L, Rouw E, Pina M, Volta A and Oudesluys-Murphy AM (2008) ESPGHAN's 2008 recommendation for early introduction of complementary foods: How good is the evidence? Maternal and Child Nutrition 7: $335-341$.

Chandra RK (2002) Breastfeeding, hydrolysate formulas and delayed introduction of selected foods in the prevention of food hypersensitivity and allergic disease. Nutrition Research 22: 125-135.

Commission for European Communities (2001) European Governance: A White Paper. COM(2001)428 final. Brussels, 25.7.2001. Brussels: Commission for European Communities. 
Delisle H (2002) Programming of Chronic Disease by Impaired Fetal Nutrition. Department of Nutrition for Health and Development. World Health Organisation.

Di Giraldamo AM, Grummer-Strawm LM and Fein SB (2003) Do perceived attitudes of physicians and hospital staff affect breast feeding decisions? Birth 30(2): 94-100.

ESPGHAN Committee on Nutrition (2008) Complementary feeding: A commentary by ESPGHAN Committee on Nutrition. Journal of Pediatric Gastroenterology and Nutrition 46: 99-110.

European Commission, Directorate of Public Health and Risk Assessment (2004) Protection, Promotion and Support of Breastfeeding in Europe: A Blueprint for Action. Luxembourg: European Commission.

European Union (2000) EU's communication on the precautionary principle. Brussels. Available at: http:// www.gdrc.org/u-gov/precaution-4.html (accessed August 2010).

Fewtrell MS, Morgan JB, Dugan C, Gunnlaugsson G, Hibberd PL, Lucas A and Kleinman RE (2007) Optimal duration of exclusive breastfeeding: What is the evidence to support current recommendations? American Journal of Clinical Nutrition 85: 635S-638S.

Foss K and Southwell BG (2006) Infant feeding and the media: The relationship between "Parents magazine" content and breastfeeding 1972-2000. International Breastfeeding Journal 1(10), doi: 10.1186/17464358-1-10

Friedman DB, Laditka JN, Laditka SB and Mathews AE (2010) Cognitive health messages in popular women's and men's magazines, 2006-2007. Preventing Chronic Disease 7. Available at: http://www.cdc.gov/ pcd/issues/2010/mar/09_0021.htm (accessed 5 September 2011).

Gage H, Raats M, Williams P, Egan B, Jakobik V, Laitinen K, Martin-Bautista E, Schmid M, von Rosen-von Hoewel J, Campoy C, Decsi T, Morgan J and Koletzko B (2011) Developmental origins of health and disease: The views of first-time mothers in 5 European countries on the importance of nutritional influences in the first year of life. American Journal of Clinical Nutrition 94: 2018S-2024S.

Gollust SE and Lantz PM (2009) Communicating population health: Print news media coverage of type 2 diabetes. Social Science and Medicine 69: 1091-1098.

Hoddinott P and Pill R (2000) A qualitative study of women's views about how health professionals communicate about infant feeding. Health Expectations 3(4): 224-233.

Horta BL, Bahl R, Martines JC and Victora CG (2007) Evidence of the long term effects of breastfeeding: Systematic review and meta-analyses. Prepared for the Department of Child and Adolescent Health (CAH) WHO. Available at: http://whq.libdoc.who.int/publications/2007/9789241595230_eng.pdf (accessed 28 June 2010).

Jensen JD (2008) Scientific uncertainty in news coverage of cancer research: Effects of hedging on scientists' and journalists' credibility. Human Communication Research 34: 347-369.

Jones S, Andrews KL, Tapsell L, Williams P and McVie D (2008) The extent and nature of health messages in magazine food advertising in Australia. Asian Pacific Journal of Clinical Nutrition 17(2): 317-324.

Kohlhuber M, Rebham B, Schwegler U, Koletzko B and Fromme H (2008) Breastfeeding rates and duration in Germany: A Bavarian cohort study. British Journal of Nutrition 99: 1127-1132.

Kramer MS, Matush L, Vanilovich I, Platt R, Bogdanovitch N and Sevkovskaya Z (2007) Promotion of Breastfeeding Intervention Trial (PROBIT) study group. British Medical Journal 335: 815-820.

Lee RG and Garvin T (2003) Moving from information transfer into information exchange in health care. Social Science and Medicine 5: 449-464.

Martin-Bautista E, Gage H, von Rosen-von Hoewel J, Jakobik V, Laitinen K, Schmid M, Morgan J, Williams P, Decsi T, Campoy C, Koletzko B and Raats M (2010) Lifetime health outcomes of breast-feeding: A comparison of policy documents of five European countries. Public Health Nutrition 13(10): 1653-1662.

Mathews AE, Laditka SB, Laditka JN and Friedman DB (2009) What are the top-circulating magazines in the United States telling older adults about cognitive health? American Journal of Alzheimer's Disease and Other Dementias 24:302-312.

May T (1993) Social Research: Issues, Methods, Process. Buckingham: Open University Press.

Meister K (2004) Nutrition Accuracy in Popular Magazines (January 2000-December 2002). New York: American Council on Science and Health. 
Moriarty CM, Jensen JD and Stryker JE (2010) Frequently cited sources in cancer news coverage: A content analysis examining the relationship between cancer news content and source citation. Cancer Causes and Control 21: 41-49.

Murphy E, Parker S and Phipps C (1998) Competing agendas in infant feeding. British Food Journal 100: $128-132$.

Nichol A, Thayaparan B, Newell M-L and Rundall P (2002) Breast feeding policy, promotion and practice in Europe: Results of a survey of non-governmental organisations. Journal of Nutritional and Environmental Medicine 12: 255-264.

O'Cathian A, Walters SJ, Nicholl JP, Thomas KJ and Kirkham M (2002) Use of evidence based leaflets to promote informed choice of maternity care: A randomised controlled trial in everyday practice. British Medical Journal 324: 643-646.

Ogden J (2007) Health Psychology: A Textbook, 4th edition. Buckingham: Open University Press.

Organisation of Economic Cooperation and Development (2009) Family data base COI.5. Breastfeeding rates. OECD, Social Policy Division - Directorate of Employment Labour and Social Affairs. Available at: www.oecd.org/els/social/family/database (accessed 13 December 2011).

Politi MC, Han PKJ and Col NF (2007) Communicating the uncertainty of harms and benefits of medical interventions. Medical Decision Making 27: 681-695.

Potter B, Sheeskoka J and Valaitis R (2000) Content analysis of infant feeding messages in Canadian women's magazines 1945-95. Journal of Nutrition Education 32(4): 196-203.

Renfrew M, Dyson L, Herbert G, McFadden A, McCormick F, Thomas J and Spiby H (2008) Developing evidence-based recommendations in public health: Incorporating the views of practitioners, service users and user representatives. Health Expectations 11: 3-15.

Rogers RW (1983) Cognitive and physiological processes in fear appeals and attitude change: A revised theory of protection motivation. In: Cacioppo J and Petty R (eds) Social Psychophysiology. New York: Guilford Press, pp. 153-176.

Shaw R, Wallace LM and Bansal M (2003) Is breast best? Perceptions of infant feeding. Community Practice 76: 299-303.

Singhal A, Wells J, Cole TJ, Fewtrell M and Lucas A (2003) Programming of lean body mass: A link between birth weight, obesity, and cardiovascular disease? American Journal of Clinical Nutrition 77(3): 726-730.

Slater MD, Long M, Bettinghaus EP and Reineke JB (2008) News coverage of cancer in the U.S.: A national sample of newspapers, television and magazines. Journal of Health Communication 13: 523-537.

Slater MD, Hayes AF, Reineke JB, Long M and Bettinghaus EP (2009) Newspaper coverage of cancer prevention: Multilevel evidence for knowledge-gap effects. Journal of Communication 59: 514-533.

Stewart-Knox B, Gardiner K and Wright M (2003) What is the problem with breastfeeding? A qualitative analysis of infant feeding perceptions. Journal of Human Nutrition and Dietetics 16: 265-273.

Virtanen SM and Knip M (2003) Nutritional risk predictors of beta-cell autoimmunity and type I diabetes at young age. American Journal of Clinical Nutrition 78: 1053-1067.

Von Kries R, Koletzko B, Sauerwald T, Von Mutius E, Barnert D, Grunert V and Von Voss H (1999) Breast feeding and obesity: Cross sectional study. British Medical Journal 319(7203): 147-150.

Weiner J (2001) The Economic Benefit of Breastfeeding: A Review and Analysis. Food Assistance and Nutrition Report no. 13. Washington DC: US Department of Agriculture.

World Health Organisation (2001) Global Strategy of Infant and Young Child Feeding: The Optimal Duration of Exclusive Breast Feeding. Geneva: WHO.

World Health Organisation (2007a) Proposed Second Action Plan for Food and Nutrition Policy, 2007-12. Copenhagen: WHO Regional Office for Europe.

World Health Organisation (2007b) Evidence of the Long Term Effects of Breastfeeding. Geneva: WHO.

World Health Organisation Europe (2003) Comparative Analysis of Food and Nutrition Policies in WHO European Member States. Report. Geneva: WHO.

World Health Organisation Europe (2007) Proposed Second Action Plan for Food and Nutrition Policy, 2007-2012. Consultation document. 


\section{Author biographies}

The authors, many of whom are well known in their fields, come from a variety of disciplines, including nutrition, medicine, health services, and statistics. They have a collective interest in the public health impact of infant feeding choices. Heather Gage, contributed to the analysis and wrote the first draft; Julia Von Rosen-Von Hoewel, Kirsi Laitinen, Viktoria Jakobik, Elena Martin-Bautista, Martina Schmid, Bernadette Egan, collected data and contributed to the analysis; Jane Morgan, Peter Williams, contributed to the analysis; Monique Raats conceived the study; all authors contributed to the design and read and approved the final manuscript. 